\title{
A Method for Calculating Oil Field Relative Permeability Curve by Using Water Drive Characteristic Curve in High Water Cut Stage
}

\author{
Juan Du \\ CNOOC Ltd.-Tianjin, Tianjin, China \\ Email:dujuan@cnooc.com.cn
}

How to cite this paper: Du, J. (2022). A Method for Calculating Oil Field Relative Permeability Curve by Using Water Drive Characteristic Curve in High Water Cut Stage. Journal of Geoscience and Environment Protection, 10, 47-54.

https://doi.org/10.4236/gep.2022.102004

Received: January 19, 2022

Accepted: February 15, 2022

Published: February 18, 2022

Copyright $\odot 2022$ by author(s) and Scientific Research Publishing Inc. This work is licensed under the Creative Commons Attribution International License (CC BY 4.0).

http://creativecommons.org/licenses/by/4.0/

(c) (i) Open Access

\begin{abstract}
With the production of strong bottom water reservoir, it will soon enter the ultra-high water cut stage. After entering the ultra-high water cut period, the main means of stable production is liquid extraction. Large liquid volume has a certain impact on the physical property distribution and fluid seepage law of the oilfield. The relative permeability curve measured according to the industry standard is not used for the prediction of development indicators and the understanding of the dynamic law of the oilfield. In order to understand the characteristics of water drive law in high water cut stage of water drive oilfield, starting from the water drive characteristic curve in high water cut stage, the method for calculating the relative permeability curve is deduced. Through numerical simulation verification and fitting the actual production data, it is confirmed that the obtained relative permeability curve is in line with the reality of the oilfield, It can provide some guiding significance for understanding the production law and water drive law of strong bottom water reservoir in ultra-high water cut stage.
\end{abstract}

\section{Keywords}

Strong Bottom Water Reservoir, High Water Cut Stage, Water Drive Curve, Relative Permeability Curve

\section{Introduction}

In reservoir engineering research, the relative permeability curve is very important for understanding the reservoir law. With the continuous production of strong bottom water reservoir, the water cut continues to rise, showing the "fac- 
tory" shaped water cut rise characteristics, and soon enters the ultra-high water cut stage. In order to stabilize production in the ultra-high water cut stage, it is mainly through liquid extraction. Through experiments, it is found that under the production conditions of a large amount of liquid, the physical properties of the oilfield will change. At this time, the conventional relative permeability experiment cannot describe the water drive law in the ultra-high water cut period, because it can not accurately reflect the physical property distribution characteristics and oil-water seepage law under the conditions, and cannot meet the fine description of the remaining oil in the ultra-high water cut period of strong bottom water reservoir.

It takes a long time to re-coring and conduct the relative permeability experiment, and the cost is large. At present, there are many methods to calculate the oil-water two-phase relative permeability curve through the water drive curve of the conventional reservoir, such as the new method and application of calculating the reservoir relative permeability curve proposed by Huang Xiangfeng in 2013 and the new method of calculating the relative permeability curve based on the water drive curve proposed by Tang Lin in 2013, Du Dianfa proposed in 2013 to calculate the relative permeability curve by using type a water drive characteristic curve (Chen et al., 2005; Dai et al., 2011; Xu et al., 2011; Jackson et al., 2005; Luo et al., 2007), but these methods are aimed at ordinary reservoirs, and the water drive curve used is not applicable to the high water cut period of strong bottom water reservoirs. In order to quickly and accurately calculate the relative permeability curve under the condition of high water cut period of the oilfield, based on the water drive law characteristics of strong bottom water oilfield, the water drive characteristic curve of strong bottom water reservoir in high water cut period is investigated, such as the theoretical derivation of the relationship of water drive characteristic curve of high water cut oilfield proposed by Song Zhaojie in 2013, the derivation and application of new water drive characteristic curve of oilfield in high water cut stage proposed by Fan Haijun in 2016, the new water drive characteristic curve in ultra-high water cut stage proposed by Cui Chuanzhi in 2015, the improvement of type a water drive characteristic curve in ultra-high water cut stage proposed by Hou Jian in 2013, and the new water drive characteristic curve in ultra-high water cut stage proposed by Wang Jiqiang in 2017. Wang Jiqiang proposed the Optimization Research on water drive characteristic curve of oil field in ultra-high water cut period in 2017 (Fu, 2009; Jiang et al., 2008; Qin, 1992; Gao \& Liu,, 2002; Yang et al., 2010; Ma et al., 2012; Olabode et al., 2021; Liang et al., 2005; Yu, 1998).

Based on the investigated water drive curve in high water cut period, combined with common reservoir engineering formulas such as Buckley Leverett front advancement equation and Welge average water saturation equation, a method for calculating oil-water two-phase permeability curve by using production performance data in high water cut period of the oilfield is established in this study. 


\section{Changes of Reservoir Physical Properties under High Scouring Multiple}

A loose core was washed with oil and salt after water flooding. After drying and weighing, the porosity and permeability were tested again. After water flooding, the average porosity of 28 cores decreases from $35.6 \%$ to $35.2 \%$, decreasing by $0.4 \%$, the average permeability decreases from $4300 \times 10^{-3} \mu \mathrm{m}^{2}$ to $3200 \times 10^{-3}$ $\mu \mathrm{m}^{2}$, decreasing by $25.6 \%$, and the physical parameters change significantly.

Through microscopic observation of the cast thin section of the sample after water flooding, it can be found that the porosity and pore diameter of the core after water flooding become smaller, and the throat is mostly curved. After core water flooding, clay minerals accumulate in the pore throat of the reservoir.

The migration of sandstone particles in the process of water injection development makes the smaller particles move with the injected water, and the sandstone particles are captured by the pore throat to form the phenomenon of formation "blockage".

Through investigation, it is found that literature shows that the permeability of existing high porosity and high permeability reservoirs will also decrease after long-term water injection scouring (Chen et al., 2011). The cores in the literature were taken from Daqing Oilfield, most of which were high porosity and high permeability, with porosity of $20 \% \sim 30 \%$ and permeability of $2000 \times 10^{-3} \mu \mathrm{m}^{2} \sim$ $3000 \times 10^{-3} \mu \mathrm{m}^{2}$. After the displacement of several parallel rock samples, the permeability decreases.

Through the analysis of the causes of permeability reduction, it is found that the main factors affecting permeability are rock skeleton composition and tectonic force, rock pore structure, rock facies, particle size distribution, particle roundness and cementation degree. For medium and high permeability reservoirs, firstly, at the initial stage of water injection, the effect of injected water on reservoir rocks is mainly physical, resulting in particle migration in the reservoir, blocking pore throat and reducing permeability. Secondly, the core used in the experiment is sandstone, which contains montmorillonite, kaolinite and illite. With water injection displacement, montmorillonite expansion and kaolinite breaking, the small throat is partially blocked, so that the effective seepage radius of the pore is reduced, and the throat can be blocked, so that the small pore throat radius becomes smaller, so as to reduce the reservoir permeability. The interlayer connection of montmorillonite crystal is loose, which is easy to absorb water and expand and carry out ion exchange. The expansion in case of water can increase the volume, block the pore throat and reduce the reservoir permeability.

Through the experiment, it is found that the physical properties of the oilfield will change under the production conditions of large liquid volume. At this time, the conventional relative permeability experiment cannot describe the water flooding law in the ultra-high water cut period, because it can not accurately reflect the physical property distribution characteristics and oil-water seepage law 
under the conditions, and cannot meet the fine description of the remaining oil in the ultra-high water cut period of strong bottom water reservoir.

Under the action of high multiple water drive, the seepage law of strong bottom water reservoir has changed. Because it is necessary to deduce the relative permeability curve through the dynamic calculation of high water cut stage.

\section{Calculation Method of Oil-Water Two-Phase Relative Permeability in High Water Cut Stage of Strong Bottom Water Reservoir}

Based on the calculation model of water drive characteristic curve in high water cut period of strong bottom water reservoir, the relationship between cumulative oil production and oil-water production is as follows (Tang et al., 2013; Liu et al., 2021; Du et al., 2013).

$$
\ln N_{p}=A+B \ln \left(W_{p}+C\right)
$$

where, $A=\frac{1}{1+k} \ln \left[\frac{1}{1+k}\left(\frac{m N}{1-S_{w i}}\right)^{1 / k}\right], \quad B=\frac{1}{1+k}, \quad C=\frac{1}{1+k}\left(\frac{1-S_{w i}}{m N}\right)^{1 / k} N_{p 0}^{1+1 / k}$.

According to Buckley Leverett water drive front propulsion equation, the functional relationship between $\overline{S_{w}}$ and $S_{w e}$ is as follows [10] [11]:

$$
S_{w e}=\left(\frac{1}{1+k} \overline{S_{w}}+\frac{k}{1+k} S_{w i}\right)\left[1+\left(\frac{\overline{S_{w}}-S_{w i}}{m}\right)^{-1 / k}\right]^{-1}
$$

Under the condition that the formation pressure is maintained by water injection and the reservoir is relatively homogeneous, according to the material balance equation:

$$
\overline{S_{w}}=\frac{N_{p}\left(1-S_{w i}\right)}{N}+S_{w i}
$$

Generally, the relationship between the relative permeability ratio at the outlet of oil-water two-phase flow and the production of oil and water is related to the parameters such as viscosity and volume coefficient. The specific formula is as follows:

$$
\frac{K_{r o}}{K_{r w}}=\frac{Q_{o} \mu_{o} B_{o} \gamma_{o}}{Q_{w} \mu_{w} B_{w} \gamma_{w}}
$$

Combined with (3) and (4), the relationship between the relative permeability ratio of oil and water phases and water saturation is exponential, as follows:

$$
K_{r o} / K_{r w}=\mu_{r} /\left[\left(\overline{S_{w}}-S_{w i}\right) / m\right]^{1 / k}
$$

The values of $m$ and $k$ can be obtained from the basic data of the reservoir. According to the cumulative water production $W_{p}$ at different times, the water saturation at different times can be calculated by Equation (2), and then the oil-water relative permeability ratio under this saturation can be obtained by Equation (12). 
In general, the oil-water relative permeability function is usually expressed in exponential form, and its exponential expression [19] is as follows:

$$
\begin{aligned}
& K_{r o}=K_{r o}\left(S_{w i}\right)\left(\frac{1-S_{o r}-S_{w}}{1-S_{o r}-S_{w i}}\right)^{\beta} \\
& K_{r w}=K_{r w}\left(S_{o r}\right)\left(\frac{S_{w}-S_{w i}}{1-S_{o r}-S_{w i}}\right)^{\gamma}
\end{aligned}
$$

where: $S_{o r}$-remaining oil saturation, \%; $\beta, \gamma$-constant; $K_{r w}\left(S_{o r}\right)$, $K_{r o}\left(S_{w i}\right)$-relative permeability of water phase and oil phase at the end of production.

Divide Equation (6) by Equation (7), and take logarithm on both sides:

$$
\begin{gathered}
\lg \left(\frac{K_{r o}}{K_{r w}}\right)=\lg \left[\frac{K_{r o}\left(S_{w i}\right)}{K_{r w}\left(S_{o r}\right)}\right]+\beta \lg \left(\frac{1-S_{o r}-S_{w}}{1-S_{o r}-S_{w i}}\right)-\gamma \lg \left(\frac{S_{w}-S_{w i}}{1-S_{o r}-S_{w i}}\right) \\
\text { Suppose: } \alpha=\lg \left[\frac{K_{r o}\left(S_{w i}\right)}{K_{r w}\left(S_{o r}\right)}\right] \\
x_{1}=\lg \left(\frac{1-S_{o r}-S_{w}}{1-S_{o r}-S_{w i}}\right) \\
x_{2}=\lg \left(\frac{S_{w}-S_{w i}}{1-S_{o r}-S_{w i}}\right) \\
y=\lg \left(\frac{K_{r o}}{K_{r w}}\right)
\end{gathered}
$$

Then Equation (8) can be rewritten as follows:

$$
y=\alpha+\beta x_{1}-\gamma x_{2}
$$

where: $\alpha$ is a constant; $y, x_{1}, x_{2}$ is a composite parameter.

After obtaining the oil-water relative permeability ratio at different times from Equation (5), $x_{1}, x_{2}$ can be obtained by combining Equations (6) and (7), Calculate $\alpha, \beta, \gamma$ from Equation (12) by binary linear regression.

As is known from formula (8), the relative permeability of water phase at the end of production can be expressed as:

$$
K_{r w}\left(S_{o r}\right)=\frac{1}{10^{\alpha}}
$$

Substituting a value into Equation (13) to get $K_{r w}\left(S_{o r}\right)$. finally, the relative permeability data of oil and water under different saturations are calculated by Equation (6) and Equation (7), and then the relative permeability curve is obtained.

\section{Case Analysis}

Taking a sandstone reservoir with bottom water as an example, it is known that 
$N=2000 \times 10^{4} \mathrm{~m}^{3}, \quad \mu_{o}=4.2 \mathrm{mPa} \cdot \mathrm{s}, \quad \mu_{w}=0.5 \mathrm{mPa} \cdot \mathrm{s}, \rho_{o}=0.92 \mathrm{~g} / \mathrm{cm}^{3}$, $\rho_{w}=1.00 \mathrm{~g} / \mathrm{cm}^{3}, B_{o}=1.28, B_{w}=1.00$.

1) According to the production data of the reservoir, the results are as follows: $A, B, C$.

2) Calculation $y, x_{1}, x_{2}$. The binary linear regression is carried out through equation 12 to get $\alpha, \beta, \gamma$.

3) According to the core analysis, $S_{w i} K_{r o}\left(S_{w i}\right)$. Using (23) formula to get $K_{r w}\left(S_{o r}\right)$.

4) Finally, the oil-water relative permeability curves under different water saturation are calculated (Figure 1).

Through the actual model of the oilfield, single well fitting is used to verify. It can be seen that the recoverable reserves predicted by numerical simulation using the relative permeability curve obtained by conventional industry standards are only 235,000 cubic meters, but the actual cumulative oil production has reached 283,000 cubic meters, and the predicted recoverable reserves are lower than the current reality, which is not in line with the reality. At the same time, through the numerical simulation of the relative permeability curve calculated by the water drive characteristic curve of bottom water reservoir at high water cut stage, the recoverable reserves are 352,000 cubic meters, and there are still 69,000 cubic meters of recoverable reserves, which is more in line with the reality (Figure 2). Therefore, the new relative permeability curve obtained in this paper is in line with the reality.

\section{Applicability}

The key of solving relative permeability curve in this method is accurate fitting, so the selection of data is particularly important. If the production data in production decline stage does not conform to the change law of water drive characteristic curve in high water cut stage of bottom water reservoir, this method is not applicable.

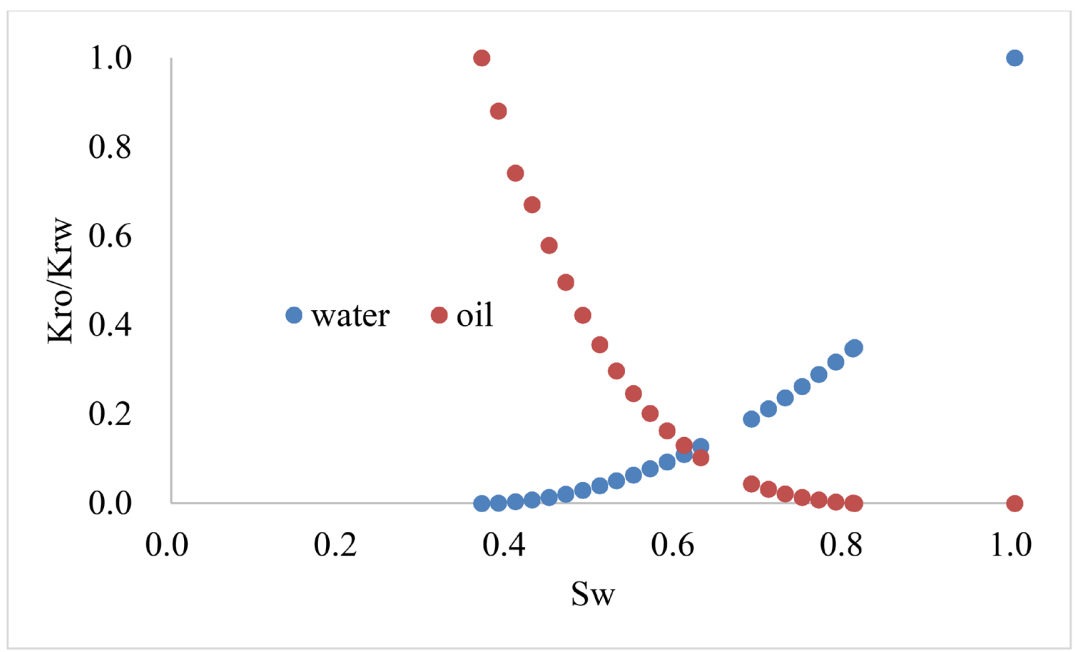

Figure 1. Oil water relative permeability curve. 


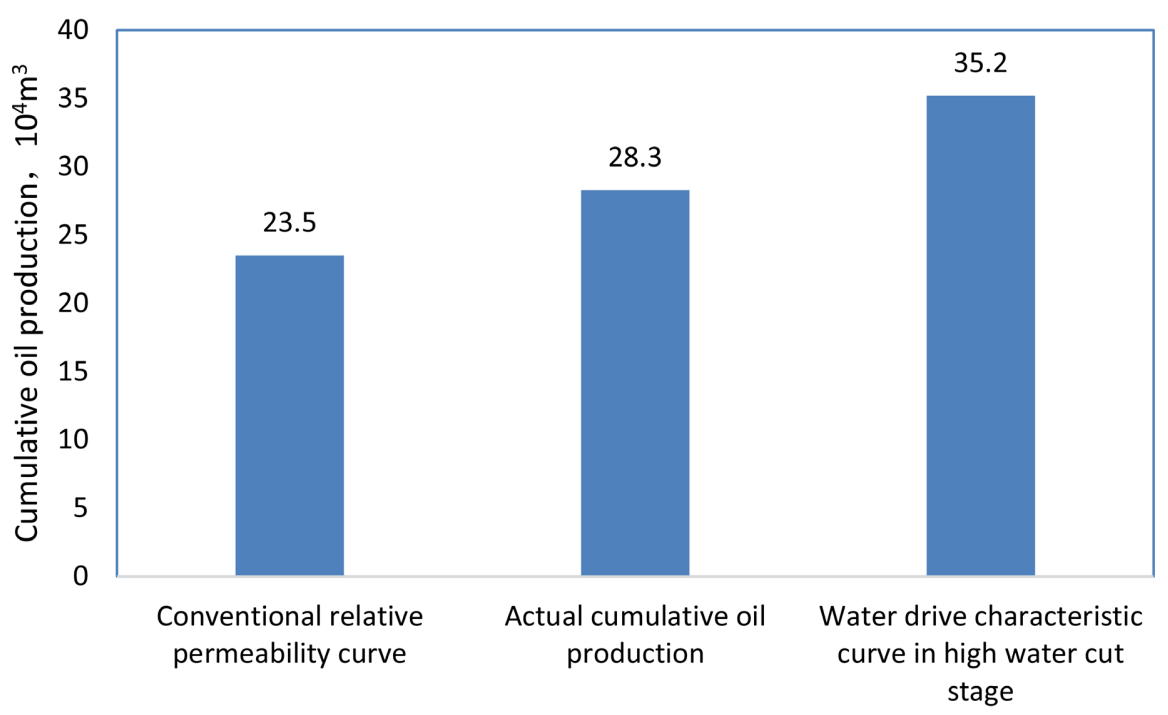

Figure 2. Comparison of cumulative oil production prediction.

\section{Conclusion}

1) Through the core experiment, it is found that under the production conditions of a large amount of liquid, the physical properties and seepage law of the oilfield will change. At this time, the conventional relative permeability experiment cannot describe the water displacement law in the ultra-high water cut period, because it can not accurately reflect the physical property distribution characteristics and oil-water seepage law under the conditions, and cannot meet the fine description of the remaining oil in the ultra-high water cut period of strong bottom water reservoir.

2) In this paper, the formula for calculating the relative permeability curve of oil and water phases by using the water drive characteristic curve in the high water cut stage of strong bottom water reservoir is derived, and a new method for deriving and calculating the relative permeability curve of oil and water phases through the actual production data in the high water cut stage of strong bottom water reservoir is provided.

\section{Conflicts of Interest}

The author declares no conflicts of interest regarding the publication of this paper.

\section{References}

Chen, X. F., Liu, F., Wang, B. et al. (2011). Variation of Permeability of High Porosity and High Permeability Reservoir under Long-Term Scouring Condition. Daqing Petroleum Geology and Development, 30, 84-87.

Chen, Z., Hao, Y. P., \& Chen, H. (2005). The Calculation Method of Oilwater Relative Permeability by Unsteady State. Fault Block Oil \& Gas Field, 12, 41-43.

Dai, S. Q., Fu, B., Hong, X. E. et al. (2011). The Methods to Fit the Curve of Integrated Relative Permeability in Reservoir. Reservoir Evaluation and Development, 1, 1-4. 
Du, D. F., Lin, X. Y., Ba, Z. C. et al. (2013). Calculation of Relative Permeability Curve with Type A Characteristic Curve of Water Drive. Special Oil \& Gas Reservoirs, 20, 93-96.

Fu, J. M. (2009). Influencing Factors of Abnormal Oil/Water Relative Permeability Curve. Petroleum Geology and Recovery Efficiency, 16, 74-76.

Gao, W. J., \& Liu, Y. (2002). The Relationship of the Production Decline and Water Drive Curve. Fault Block Oil \& Gas Field, 9, 45-49.

Jackson, M. D., Saunders, J. H., \& Addiego-Guevara, E. A. (2005). Development and Application of New Downhole Technology to Detect Water Encroachment toward Intelligent Wells. In SPE Annual Technical Conference and Exhibition (SPE97063). SPE. https://doi.org/10.2118/97063-MS

Jiang, W. D., Ren, Y. B., Zhang, Y. L. et al. (2008). Study on Oil and Water Relative Permeability and Water Flooding Efficiency in Heavy Oil Reservoirs. Petroleum Geology \& Oilfield Development in Daqing, 27, 50-53.

Liang, S. B., Zhao, H. Y., Song, H. W. et al. (2005). Method of Calculating Relative Permeability Curve by Production Data. Petroleum Geology \& Oilfield Development in Daqing, 24, 56-58.

Liu, Y.-X., Tan, J., Cai, H. et al. (2021). Derivation of Water Flooding Characteristic Curve for Offshore Low-Amplitude Structural Reservoir with Strong Bottom Water. Journal of Petroleum Exploration and Production Technology, 11, 3267-3276. https://doi.org/10.1007/s13202-021-01240-Z

Luo, Z. F., Huagn, B. G., Wagn, N. T. et al. (2007). A Calculation Method for Relative Permeability of Low Permeability Reservoir. Fault-Block Oil and Gas Field, 14, 47-49.

Ma, Y. L., Zhao, Z. J., Zhang, Z. H. et al. (2012). Relative Permeability Curve Computing Method in Low Permeability and Viscosity Reservoirs-Type IV Water Drive Characteristic Curve Method. Reservoir Evaluation and Development, 2, 28-31.

Olabode, O., Isehunwa, S., Orodu, O. et al. (2021) Optimizing Productivity in Oil Rims: Simulation Studies on Horizontal Well Placement under Simultaneous Oil and Gas Production. Journal of Petroleum Exploration and Production Technology, 11, 385-397. https://doi.org/10.1007/s13202-020-01018-9

Qin, T. L. (1992). Practical Reservoir Engineering Method (pp. 38-100). Petroleum Industry Press.

Tang, L., Guo, X., Miao, Y. P. et al. (2013). A New Method of Calculating Relative Permeability Curves by Water Drive Curves. Reservoir Evaluation and Development, 3, 16-19.

Xu, H., Tian, R. B., Li, S. et al. (2011). Reservoir Sensitivity and Oil-Water Relative Permeability of the Third Member of Funing Formation in Zhangjiaduo. Reservoir Evaluation and Development, 1, 48-51.

Yang, Y., Zhou, W., Qiu, K. T. et al. (2010). A New Method of Calculating Relative Permeability Curve. Petroleum Geology and Recovery Efficiency, 17, 105-107.

$\mathrm{Yu}$, Q. T. (1998). A New Generalized Water Drive Curve. Petroleum Exploration and Development, 25, 48-50. 